\title{
Asymptomatic bacteriuria in pregnancy: what is the validity of urine sediment microscopy as a screening tool in a low resource setting?
}

\author{
Rashmi Polnaya ${ }^{1 *}$, Amritha Bhandary ${ }^{2}$
}

\begin{abstract}
${ }^{1}$ Department of Obstetrics and Gynecology, Kasturba Medical College, Mangaluru, Manipal Academy of Higher Education, Karnataka, India

${ }^{2}$ Department of Obstetrics and Gynecology, AJ Institute of Medical Sciences, Mangaluru, Karnataka, India
\end{abstract}

Received: 19 March 2020

Accepted: 22 April 2020

\author{
*Correspondence: \\ Dr. Rashmi Polnaya, \\ E-mail: rashmipolnaya@gmail.com
}

Copyright: (C) the author(s), publisher and licensee Medip Academy. This is an open-access article distributed under the terms of the Creative Commons Attribution Non-Commercial License, which permits unrestricted non-commercial use, distribution, and reproduction in any medium, provided the original work is properly cited.

\section{ABSTRACT}

Background: Asymptomatic bacteriuria in pregnancy should be screened and treated to reduce the risk of morbidity and mortality. Urine culture is the recommended test. In low resource setting with large patient load urine culture in all pregnant patients is not feasible. In this study authors have assessed the validity of urine microscopy in the screening of asymptomatic bacteriuria in pregnancy.

Methods: Midstream clean catch urine specimen collected from 675 pregnant women was subjected to urine sediment microscopy and culture. It was considered screen positive if pus cells were $>5 / \mathrm{HPF}$. Asymptomatic bacteriuria was diagnosed if there were $>/=100000 \mathrm{CFU}$ of a single uropathogen per ml. Results obtained were statistically analysed for the prevalence of asymptomatic bacteriuria, sociodemographic and medical risk factors, causative organisms, antibiotic sensitivity and validity of urine sediment microscopy in detecting asymptomatic bacteriuria.

Results: The incidence of asymptomatic bacteriuria in our study was $10.2 \%$. The incidence was higher in the age group between 20-30 years, in gravida 3 and above, in upper lower and lower socioeconomic status, in women with hyperglycemia in pregnancy and anaemia. E. coli was the commonest bacterial isolate in culture positive cases. Bacterial isolates had poor sensitivity for Ampicillin, amoxicillin and nitrofurantoin and good sensitivity for cephalosporins and aminoglycosides. The sensitivity, specificity, positive and negative predictive values for urine microscopy was $43 \%, 85 \%, 25 \%$ and $93 \%$ respectively.

Conclusions: This study shows poor sensitivity and positive predictive value and good specificity and negative predictive value.

Keywords: Asymptomatic bacteriuria, Screening, Urine culture, Urine microscopy

\section{INTRODUCTION}

Asymptomatic bacteriuria $(\mathrm{AB})$ indicates persistent actively multiplying bacteria within the urinary tract without urinary symptoms. ${ }^{1} 20-40 \%$ of pregnant women with untreated $\mathrm{AB}$ can progress to acute pyelonephritis which is associated with increased risk of maternal and perinatal morbidity and mortality.
Therefore, guidelines have been made to screen for $\mathrm{AB}$ in all pregnant women and treat the same. ${ }^{1}$ Urine culture and sensitivity is the gold standard investigation for screening $\mathrm{AB}$. In low resource settings with substantial patient load urine culture is not cost effective. In study hospital authors screen for $\mathrm{AB}$ using urine microscopy. This study was conducted to assess the validity of urine microscopy in detecting AB. 


\section{METHODS}

This was a prospective cross-sectional study conducted at Government Lady Goschen Hospital, Mangaluru, Karnataka, India. Study period was from October 2007 to September 2008. Study population included pregnant women attending antenatal clinics during the study period. Women with symptoms of urinary tract infection and history of antibiotic use in the past two weeks were excluded from the study.

Midstream clean catch urine sample was collected in sterile containers and specimen were sent to microbiology laboratory within one hour for processing. One part of the sample was sent for urine sediment microscopy where about 5-10 $\mathrm{ml}$ of urine was centrifuged at $2000 \mathrm{rpm}$ for 5 minutes and the sediment was studied in approximately $10 \mathrm{HPF}$ to detect pus cells and bacteria and then averaged. It was considered screen positive if pus cells were $>5 / \mathrm{HPF}$.

Another part of the urine specimen was sent for culture and sensitivity testing. Urine was plated onto sheep blood agar plate and MacConkey agar plate with $0.001 \mathrm{ml}$ loop by calibrated loop method. The plates were incubated aerobically and read at 24 and 48 hours. AB was diagnosed if there were $>/=100000 \mathrm{CFU}$ of a single uropathogen per $\mathrm{ml}$. Isolates were identified to species level using standard methods and their antibiotic sensitivities were tested using Kirby Bauer disc diffusion technique. Urine samples producing non-significant or mixed growth were excluded from the study. Participation of the women was voluntary after obtaining valid consent. All information obtained was kept confidential and women with $\mathrm{AB}$ were treated with antibiotics.

\section{Statistical analysis}

Data was analysed using SPSS 17.0. Results obtained were analysed for the prevalence of $A B$, sociodemographic factors such as age, parity and socioeconomic status (using modified Kuppuswamy scale) and medical risk factors such as hyperglycemia in pregnancy and anemia. Chi square test was used to assess difference between proportions and $p$ value of $<0.05$ was considered as statistically significant. Bacterial isolates and their antibiotic sensitivity were analysed. Validity of urine sediment microscopy in detecting AB was tested by calculating sensitivity, specificity, positive and negative predictive values.

\section{RESULTS}

Among the 675 pregnant women who were screened 69 were diagnosed with $\mathrm{AB}$. Prevalence of $\mathrm{AB}$ was calculated to be $10.2 \%$. The sociodemographic factors and medical risk factors are shown in Table 1.

Table 1: Sociodemographic factors and medical risk factors in cases with asymptomatic bacteriuria.

\begin{tabular}{|c|c|c|c|c|}
\hline Risk factors & $\begin{array}{l}\text { Positive urine } \\
\text { culture, } \mathbf{N}(\%)\end{array}$ & $\begin{array}{l}\text { Total } \\
\text { number }\end{array}$ & $\begin{array}{l}\text { Chi square } \\
\text { value }\end{array}$ & p value \\
\hline \multicolumn{3}{|l|}{ Age, years } & \multirow{4}{*}{7.59} & \multirow{4}{*}{0.02} \\
\hline$<20$ & $0(0.0 \%)$ & 60 & & \\
\hline $20-30$ & $60(12.1 \%)$ & 492 & & \\
\hline$>30$ & $9(7.3 \%)$ & 123 & & \\
\hline \multicolumn{3}{|l|}{ Parity } & \multirow{5}{*}{8.11} & \multirow{5}{*}{0.04} \\
\hline G1 & $27(9.3 \%)$ & 288 & & \\
\hline $\mathrm{G} 2$ & $18(7.6 \%)$ & 234 & & \\
\hline G3 & $18(17.6 \%)$ & 102 & & \\
\hline G4 and above & $6(11.7 \%)$ & 51 & & \\
\hline \multicolumn{3}{|c|}{ Socioeconomic status (modified Kuppuswamy scale) } & \multirow{6}{*}{21.82} & \multirow{6}{*}{$<0.001$} \\
\hline Upper & $0(0.0 \%)$ & 0 & & \\
\hline Upper middle & $3(8.3 \%)$ & 36 & & \\
\hline Lower middle & $12(4.7 \%)$ & 252 & & \\
\hline Upper lower & $36(11.7 \%)$ & 306 & & \\
\hline Lower & $18(22.2 \%)$ & 81 & & \\
\hline Hyperglycaemia in pregnancy & $24(25.8 \%)$ & 93 & 28.54 & $<0.001$ \\
\hline Anemia (haemoglobin $<11 \mathrm{~g} \%$ ) & $54(15.1 \%)$ & 357 & 19.8 & $<0.001$ \\
\hline
\end{tabular}

Mean age of study population was 24.86 (SD = 1.84, range 18-43) and majority of them were primigravidae $(42.6 \%)$ belonging to lower socioeconomic status
(45.3\%). There was a higher incidence of $A B$ in the age group of 20-30 years ( $\mathrm{p}$ value $<0.02$ ) and among third 
gravida and above ( $\mathrm{p}$ value $<0.04)$ which was statistically significant.

The incidence of $\mathrm{AB}$ was higher in those belonging to upper lower and lower socioeconomic status which was statistically significant ( $\mathrm{p}$ value $<0.001$ ). Women with hyperglycaemia in pregnancy and anaemia had a higher incidence of $A B(p$ value $<0.001)$.

The microbiologic isolates in the culture positive specimen constituted: E. coli $(60.8 \%)$, Pseudomonas (21.7\%), Klebsiella (13\%), Group B Streptococcus $(4.3 \%)$. Antibiotic sensitivity of the bacterial isolates is shown in Table 2. E. coli had good sensitivity for antibiotics such as Amikacin (78.5\%), Cefotaxim (92.8\%), Cefuroxime (92.8\%), Cotrimoxazole (64.2\%), Gentamicin (78.5\%), Norfloxacin (64.2\%) and Tobramycin $(64.2 \%)$ whereas poor sensitivity for Ampicillin (14.2\%), Amoxicillin (0\%) and Nitrofurantoin (14.2\%).

The sensitivity of urine sediment microscopy was calculated to be $0.435(0.256-0.632)$, specificity 0.851 (0.796-0.894), positive predictive value $0.25(0.142-$ $0.402)$ and negative predictive value 0.93 (0.883-0.958), $95 \%$ CI.

Table 2: Antibiotic sensitivity patterns of bacterial isolates in cases with asymptomatic bacteriuria.

\begin{tabular}{|lllll|}
\hline Antibiotics tested & $\begin{array}{l}\text { Escherichia coli } \\
(\mathbf{N = 4 2})\end{array}$ & $\begin{array}{l}\text { Pseudomonas } \\
(\mathbf{N}=\mathbf{1 5})\end{array}$ & $\begin{array}{l}\text { Klebsiella } \\
(\mathbf{N}=\mathbf{9})\end{array}$ & $\begin{array}{l}\text { Group B } \\
\text { Streptococcus }(\mathbf{N}=3)\end{array}$ \\
\hline Ampicillin & $6(14.2 \%)$ & $0(0.0 \%)$ & $0(0.0 \%)$ & $0(0.0 \%)$ \\
\hline Amoxicillin & $0(0.0 \%)$ & $0(0.0 \%)$ & $0(0.0 \%)$ & $0(0.0 \%)$ \\
\hline Amikacin & $33(78.5 \%)$ & $15(100 \%)$ & $9(100 \%)$ & $3(100 \%)$ \\
\hline Cefotaxim & $39(92.8 \%)$ & $12(80 \%)$ & $9(100 \%)$ & $0(0.0 \%)$ \\
\hline Cefuroxime & $39(92.8 \%)$ & $3(20 \%)$ & $6(66.6 \%)$ & $3(100 \%)$ \\
\hline Cotrimoxazole & $27(64.2 \%)$ & $0(0.0 \%)$ & $6(66.6 \%)$ & $3(100 \%)$ \\
\hline Gentamicin & $33(78.5 \%)$ & $3(20 \%)$ & $9(100 \%)$ & $3(100 \%)$ \\
\hline Norfloxacin & $27(64.2 \%)$ & $3(20 \%)$ & $9(100 \%)$ & $3(100 \%)$ \\
\hline Nitrofurantoin & $6(14.2 \%)$ & $0(0.0 \%)$ & $0(0.0 \%)$ & $0(0.0 \%)$ \\
\hline Netilmycin & $42(100 \%)$ & $15(100 \%)$ & $3(33.3 \%)$ & $0(0.0 \%)$ \\
\hline Nalidixic acid & $9(21.4 \%)$ & $0(0.0 \%)$ & $6(66.6 \%)$ & $0(0.0 \%)$ \\
\hline Tobramycin & $27(64.2 \%)$ & $15(100 \%)$ & $9(100 \%)$ & $0(0.0 \%)$ \\
\hline
\end{tabular}

\section{DISCUSSION}

The incidence of $\mathrm{AB}$ in this study population was $10.2 \%$. This incidence is similar to the Indian studies by Rajarathnam A et al, i.e., $13.2 \%$ and Verma A et al i.e. $12.27 \%$, whereas in western population the incidence is much lower as seen in a study by Sheiner E et al with an incidence of $2.5 \% .^{2-4}$ This may be due to lower socioeconomic status in the population catered to by study hospital as depicted in Table 1 .

Moreover, the incidence of hyperglycemia in pregnancy and anaemia are higher in study population as shown in Table 1 which are known risk factors for UTI.

The commonest organism isolated in the specimens of $\mathrm{AB}$ in this study was E. coli (60.8\%) which was comparable with other studies. 5,6

In this study authors found that there is poor bacterial sensitivity for commonly used antibiotics such as ampicillin, amoxicillin and nitrofurantoin which is comparable to other studies where they found poor bacterial sensitivity to Ampicillin but in contrast showed good sensitivity to nitrofurantoin..$^{5,6}$
A good screening test should have good sensitivity, specificity and predictive values. In this study authors found that urine sediment microscopy has poor sensitivity i.e., $43 \%$ and positive predictive value i.e., $25 \%$ and good specificity (85\%) and NPV (93\%). This finding is in contrast to earlier study by Abyad A which showed a higher sensitivity (94.4\%) and specificity (95\%) using the same cut-off values for pus cells in microscopy. ${ }^{7}$ A study by Etminan-Bakhsh $\mathrm{M}$ et al using cut off of 6 or more pus cells per HPF showed a sensitivity of $100 \%$ and specificity of $64 \%$, the drawback of this study being a small sample size. ${ }^{8}$ A study by Alfred AO et al where pus cells more than 5 per HPF and or bacteria more than or equal to one per HPF is used as cut off, sensitivity was found to be $90.9 \%$ and specificity was $49.3 \% .{ }^{9}$ In another study by Gyang MD et al using cut off as more than or equal to 2 pus cells per HPF gave a sensitivity of $66.7 \%$ and a specificity of $82.3 \%$ whereas using cut-off as more than or equal to 3 pus cells per HPF had a sensitivity of $33.3 \%$ and specificity $95.4 \%$ thus reducing the sensitivity and improving specificity. ${ }^{10}$ However, these studies have not specified if centrifuged urine specimen were used., ${ }^{9,10}$ Several recent studies have concluded that the sensitivity of various screening tests for $\mathrm{AB}$ such as dipstick tests for leukocyte esterase and nitrates and urine microscopy was 
poor. ${ }^{11-13}$ Hence guidelines for screening of $\mathrm{AB}$ in pregnancy have recommended urine culture in all pregnant women at least once during their antenatal visits after the first trimester. ${ }^{1}$ In low resource setting with a heavy patient load, urine culture in all pregnant women is not cost effective and review of all these women again after 3 days with the culture report is not feasible as there is risk of loss to follow up. On the other hand, urine microscopy is cost effective but labour intensive when compared to dipstick tests in hospitals burdened with heavy patient load. There are studies done to assess the sensitivity of automated methods for detecting significant pus cells and bacteria in urine and this may prove to be a promising screening test for low resource settings with heavy patient load. ${ }^{14}$ There is a need for studies with larger sample size in populations with higher prevalence of $\mathrm{AB}$ with validity test for various cut-offs values for pus cells in urine microscopy to improve the validity of urine microscopy as a screening tool for $\mathrm{AB}$ in pregnancy.

\section{Funding: No funding sources}

Conflict of interest: None declared

Ethical approval: The study was approved by the Institutional Ethics Committee obtained from Kasturba Medical College, Mangaluru, Karnataka, India

\section{REFERENCES}

1. U.S. preventive services task force. screening for asymptomatic bacteriuria in adults: US preventive services task force recommendation statement. JAMA. 2019;322(12):1188-94.

2. Rajarathnam A, Baby NM, Kuruvilla TS, Machado S. Diagnosis of asymptomatic bacteriuria and associated risk factors among pregnant women in Mangalore, Karnataka, India. J Clin Diagn Res. 2014;8(9):OC23-OC25.

3. Verma A, Vyas A, Shrimali L, Sharma M. Asymptomatic bacteriuria and antibacterial susceptibility during pregnancy. Int $\mathrm{J}$ Reprod contracept Obstet Gynecol. 2016;5(2):407-10.

4. Sheiner E, Mazor-Drey E, Levy A. Asymptomatic bacteriuria in pregnancy. $\mathrm{J}$ Mat-fet Neonat Med. 2009;22(5):423-27.

5. Bose AM, Sreekumary PK, Pulikkottil SK. Microbiological profile of asymptomatic bacteriuria in pregnancy. Crit Care Obst Gyne. 2016;2:5.
6. Gayathree L, Shetty S, Deshpande SR, Venkatesha DT. Screening for asymptomatic bacteriuria in pregnancy: an evaluation of various screening tests at the Hassan district hospital, India. J Clin Diagn Res. 2010;4:2702-6.

7. Abyad A. Screening for asymptomatic bacteriuria in pregnancy: urinalysis vs urine culture. J Fam Pract. 1991;33(5):471-4.

8. Etminan-Bakhsh M, Tadi S, Darabi R. Asymptomatic bacteriuria in pregnant women attending Boo-Ali Hospital Tehran Iran: Urine analysis versus urine culture. Electron Phys. 2017;9(11):5760-3.

9. Alfred AO, Matie O, Gbenga SA, Chiedozie I, Martin DU. Diagnostic characteristics of urine microscopy in detecting asymptomatic bateriuria in pregnancy using urine culture as gold standard. IOSR J Dent Med Sci. 2014;13(1):87-90.

10. Gyang MD, Dankyau M, Yohanna S, Madaki A. Is simple microscopy useful in the diagnosis of asymptomatic bacteriuria in pregnancy in primary care settings? Nigerian J Fam Prac. 2012;3(1):7-14.

11. Kacmaz B, Cakir O, Aksoy A, Biri A. Evaluation of rapid urine screening tests to detect asymptomatic bacteriuria in pregnancy. Jpn $J$ Infect Dis. 2006;59(4):261-3.

12. Mignini L, Carroli G, Abalos E, Widmer M, Amigot S, Nardin JM. Accuracy of diagnostic tests to detect asymptomatic bacteriuria during pregnancy. Obstet Gynecol. 2009;113(2 Pt 1):346-52.

13. Rogozińska E, Formina S, Zamora J, Mignini L, Khan KS. Accuracy of onsite tests to detect asymptomatic bacteriuria in pregnancy: a systematic review and meta-analysis. Obstet Gynecol. 2016;128(3):495-503.

14. Foudraine DE, Bauer MP, Russcher A. Use of automated urine microscopy analysis in clinical diagnosis of urinary tract infection: defining an optimal diagnostic score in an academic centre population. J Clin Microbiol. 2018;56(6):e02030-17.

Cite this article as: Polnaya R, Bhandary A.

Asymptomatic bacteriuria in pregnancy: what is the validity of urine sediment microscopy as a screening tool in a low resource setting? Int $\mathrm{J}$ Reprod Contracept Obstet Gynecol 2020;9:2442-5. 